\title{
The Processes in Film-Forming Solution Based on Tetraethoxysilane, Phosphoric Acid and Calcium Chloride
}

\author{
Tatyana Petrovskaya ${ }^{1, a)}$, Svetlana Kuznetsova, ${ }^{2, b)}$, Liudmila Borilo ${ }^{2, c)}$ \\ and Vladimir Kozik ${ }^{1,2, \mathrm{~d})}$ \\ ${ }^{I}$ Tomsk Polytechnic University, 30 Lenina Avenue, Tomsk 634050 Russian Federation \\ ${ }^{2}$ Tomsk State University, 36 Lenina Avenue, Tomsk 634050 Russian Federation \\ a)corresponding author: pts@tpu.ru \\ b)onm@xf.tsu.ru \\ c)borilo@mail.ru \\ ${ }^{\mathrm{d})}$ vkozik@mail.ru
}

\begin{abstract}
Physical and chemical patterns film-forming ethanol solution based on tetraethoxysilane, orthophosphoric acid and calcium chloride have been determined. Methods of photon correlation spectrometry and electrophoresis showed that colloidal particles with size up to $25 \mathrm{~nm}$ are formed in the film-forming solutions. Their stability is maintained during one day, and then $\mathrm{CaHPO}_{4}$ precipitates from the film-forming solutions. Methods of X-ray analysis, scanning electron microscopy and IR spectroscopy have shown that the dried coating solution after precipitation of $\mathrm{CaHPO}_{4}$ consists of $\mathrm{CaClH}_{2} \mathrm{PO}_{4} \cdot \mathrm{H}_{2} \mathrm{O}$ and $\mathrm{SiO}_{2}$. The formation of these substances is due to the hydrolysis of tetraethoxysilane and interaction calcium chloride with orthophosphoric acid.
\end{abstract}

\section{INTRODUCTION}

Creation of reliable orthopedic implants is one of the most complex challenges in medical materials science. The ideal implant must have ability to osteointegration, prevent bacterial adhesion, minimize risk of the origin of infections, and perform reliably biomechanical functions for long time. The greatest successes in this direction have been achieved owing to use of calcium containing bioceramic coatings which allow promoting intensifying of biocompatibility and activity as well as lead to growth of osteointegration properties of metal implants [1-2]. Biocompatibility of coatings is provided, first of all, by analogy of chemical and phase composition of mineral component of biological bone tissue. Chemical similarity is not enough to ensure bioactivity and effective integration with natural bone. Steady adhesion and growth of bone cells (osteoblasts) on implant surface (osteoconduction), immobilization of stem cells from blood flow and support of their differentiation in osteogenic cells (osteoinduction) are phenomena leading to formation of bond with bone and are defined with special surface properties which depend on the way of production.

Influence of surface architecture on its bioactivity was shown in many investigations [3-6]. According to data [7], for obtaining calcium phosphate materials on titanium substrates are widely used of sol-gel method. Using the sol-gel method in the preparation of calcium phosphate coating on a substrate allows improve the bioactivity titanium implant by changes the surface and the micro and nanotopographic characteristics. Investigation of structural and morphological peculiarities of titanium implant with calcium phosphate layer is given in papers [8-10]. However, literature has no information about chemical processes of formation of calcium phosphate thin-film coatings from film forming solutions. It is known that the surface condition of any materials determined by the way the preparation and knowledge of physical and chemical patterns receiving material enables to control the synthesis process and to obtain substances with desired properties.

The aim of the present work establish the processes occurring in the film-forming solution (FFS) on the based on ethanol, tetraethoxysilane (TEOS), phosphoric acid and calcium chloride in the time and obtain of calcium phosphate thin film. 


\section{EXPERIMENTAL PART}

Film-forming solution (FFS) was prepared in $96 \%$ ethanol dissolving tetraethoxysilane, orthophosphoric acid, and calcium chloride (Russian grade) in it $\left(\mathrm{C}\left(\mathrm{Si}\left(\mathrm{OC}_{2} \mathrm{H}_{5}\right)_{4}=\mathrm{C}\left(\mathrm{H}_{3} \mathrm{PO}_{4}\right)=\mathrm{C}\left(\mathrm{CaCl}_{2}\right)=0.3 \mathrm{~mol} / \mathrm{l}\right)\right.$. The molar ratio of $\mathrm{Ca} / \mathrm{P}=1$ in the solution. The resulting solution was kept at room temperature for two hours. Thereafter, using photon correlation spectroscopy (PCS), determined by the radius of the dispersed phase particles in solution. The size of FFS particles was defined with photon correlation spectrometer (PCS) UNICOR - SP (made in Russia) in homodyne detection mode. Monochromatic emission of a He - Ne laser (LG-38, emission power $\sim 50 \mathrm{~mW}, \lambda=655 \mathrm{~nm}$ ), passing through the sample compartment was scattered by dispersion phase particles and fixed with photodetector operating in photon accounting system (PEM-136, $\mathrm{f}_{\max }=$ $35 \mathrm{MHz}$, noise level 10-40 pulse/s), which signal entered the multichannel digital correlator PhotoCor-Sp. Information about scattered emission was processes with the help of special computer program PhotoCor. Average radius of particles was calculated from diffusion coefficient according to Stokes - Einstein formula: D $=\mathrm{kT} / 6 \pi \eta \mathrm{r}$, where $\mathrm{k}$ is Boltzmann constant, $\mathrm{T}$ is absolute temperature, $\eta$ is solvent viscosity (ethanol). Diffusion coefficient was defined by scattered light spectrum: $\mathrm{G}=\mathrm{Dq}^{2}$, where $\mathrm{q}$ is module of wave vector scattering. Charge of colloidal particles was defined with an electrophoretic method: FFS was placed in U-tube and coagulation which occurred under potential difference applied to solution was observed.

After keeping the solution for a day formed precipitate became of white color. Precipitated disperse phase was separated from dispersive medium. The system obtained again was analyzed: "precipitate" with IR, X-ray, and MRSA method, FFS after precipitation - with IR spectroscopy, PCS, electrophoretic, and X-ray analysis. Precipitate composition was defined by X-ray phase analysis method with a diffractometer Rigaku Miniflex 600 (made in Japan) using $\mathrm{CuK}_{\alpha}$-emission in the range of $2-90^{\circ}(2 \theta)$ with increment of $0.02^{\circ}$ and scan rate of 2 $\%$ min. Identification of diffraction maxima was performed using JSPDS database. Calculation of coherent emission field by which crystallite size was estimated was performed according to Scherrer equation which connects integral line width with crystallite size:

$$
\mathrm{D}=\lambda / \beta \cos \theta
$$

Solubility in ethanol precipitate was determined in the following way: the sample was dissolved in $96 \%$ ethanol at room temperature; aged for 14 days, then the precipitate was filtered off and the mother liquor was dried. Then the dried mother liquor was dissolved in water. The content of $\mathrm{Ca}^{2+}$ ions in aqueous solution was determined by titration with Trilon B.

Surface morphology and quantitative elemental analysis of the precipitate and dried FFS were researched with the scanning electron microscope Hitachi TM3000 (Japan) at acceleration voltage $15 \mathrm{kV}$ in conditions of mode of charge removal from the sample (electron gun $5 \times 10^{2} \mathrm{~Pa}$, sample chamber $30-50 \mathrm{~Pa}$ ), using energy dispersive spectrometer QUANTAX 70 (Japan) for elemental analysis. The error of quantitative elemental analysis is $\pm 5 \%$. The error of qualitative elemental analysis is $- \pm 1 \%$.

Infrared (IR) spectra of the precipitate and mother solution as well as FFS dried at $60{ }^{\circ} \mathrm{C}$ were collected with the spectrometer Agilent Cary 630 FTIR (made in USA) in frequency range of 400-4000 $\mathrm{cm}^{-1}$.

Calcium phosphate films on substrates of monocrystalline silicon were obtained from FFS on the first day of its preparation. The solution was applied on a substrate by centrifugation method (speed centrifugation 3000 $\mathrm{rev} / \mathrm{s})$. Thickness (d) and refraction index (n) of the films was defined with the help of the ellipsometer SE400 (Germany).

\section{RESULTS AND DISCUSSION}

TABLE 1. Data of PCS method for FFS with TEOS- $\mathrm{CaCl}_{2} \cdot 2 \mathrm{H}_{2} \mathrm{O}-\mathrm{H}_{3} \mathrm{PO}_{4}$ composition

\begin{tabular}{ccc}
\hline $\begin{array}{c}\text { Time of FFS exposure after preparation, } \\
\mathbf{h}\end{array}$ & $\begin{array}{c}\text { Time of signal } \\
\text { accumulation }\left(\tau_{\mathbf{a}}\right), \mathbf{s}\end{array}$ & $\begin{array}{c}\text { Particle radius, } \\
\mathbf{n m}\end{array}$ \\
\hline 2 & 198 & 19 \\
2 & 250 & 5 \\
2 & 335 & 0.8 \\
2 & 396 & 0.3 \\
4 & 21 & 19 \\
4 & 169 & 25 \\
4 & 211 & 23 \\
4 & 237 & 22 \\
\hline
\end{tabular}


Interaction between FFS components with formation of colloidal solution takes place in the first day of FFS preparation. According to photon correlation spectroscopy (PCS) radius of the dispersed phase particles in solution after its exposure at room temperature during two hours is from $0.3 \mathrm{~nm}$ to $19 \mathrm{~nm}$ (Table 1). After a four-hour exposure solution small particle size is increased to $25 \mathrm{~nm}$, and scatter size decreases. The radii of the particles in the FFS are in the range 19-25 $\mathrm{nm}$. During one day the particles are enlarged, visualized, and their sedimentation is observed.

According to results of X-ray (Fig. 1) phase analysis precipitate represents calcium hydrophosphate (monetite).

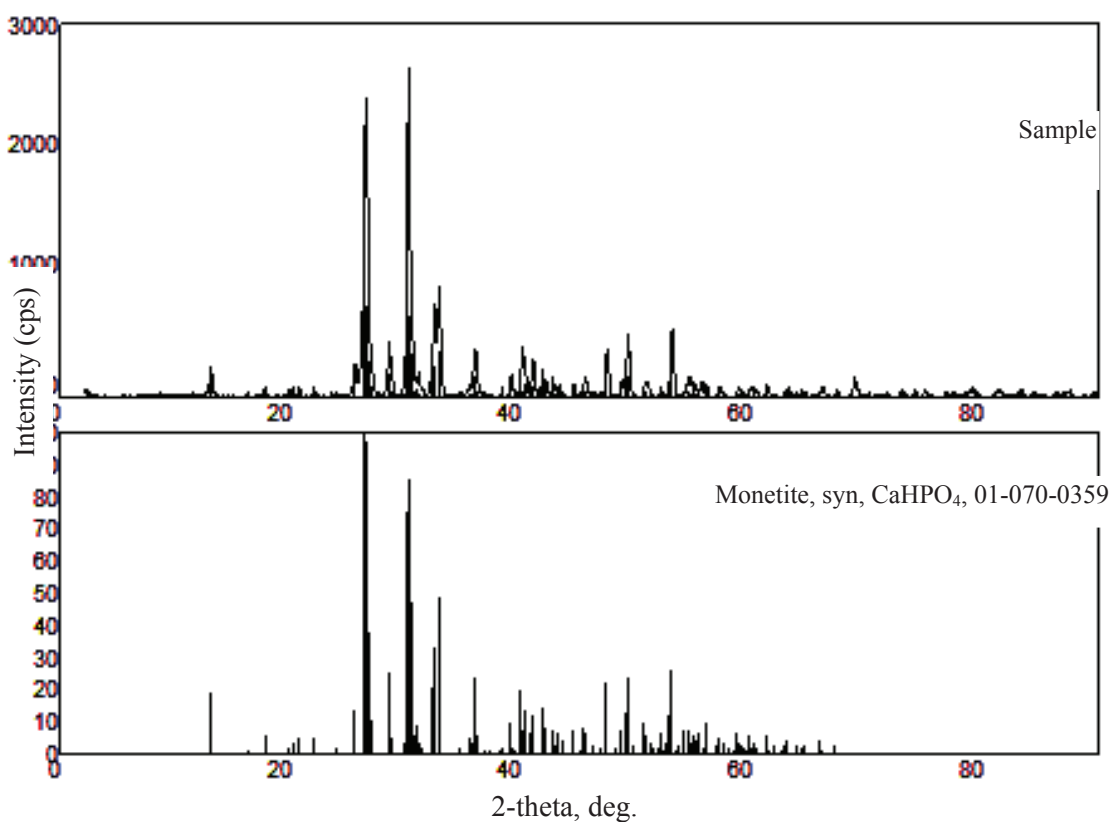

FIGURE 1. X-ray photograph of the precipitate.

Calcium hydrophosphate is characterized with triclinic structure with lattice parameters: $a=6.925 \AA, b=$ $6.641 \AA$, and $c=7.013 \AA$ and angles $\alpha=96.34^{\circ}, \beta=103.82^{\circ}$, and $\gamma=88.33^{\circ}$. Average value of $\mathrm{CaHPO}_{4}$ crystallite calculated according to Scherrer equation is $30 \mathrm{~nm}$. Presence of calcium hydrophosphate in the solid precipitate is pointed out by results of quantitative X-ray microanalysis (Table 2).

TABLE 2. Presults of quantitative X-ray microanalysis of the solid precipitate of FSS.

\begin{tabular}{ccc}
\hline \multicolumn{3}{c}{$\begin{array}{c}\text { Content of CaHPO } \\
\text { 4 }, \\
\text { experimentally determined / calculated, at. } \%\end{array}$} \\
\hline Ca & $\mathbf{P}$ & $\mathbf{O}$ \\
\hline $13.31 \pm 0.02 / 12.5$ & $12.79 \pm 0.03 / 12.5$ & $55.84 \pm 0.06 / 50$ \\
\hline
\end{tabular}

However, as seen from the results of X-ray quantitative microanalysis in the precipitate $\mathrm{CaHPO}_{4}$ has a silicon impurity (Fig.2). Elevated levels of atomic percent oxygen indicate that the silicon is a part of the impurities in the form of silicon dioxide (Table 2). (Method determines the total oxygen content). 


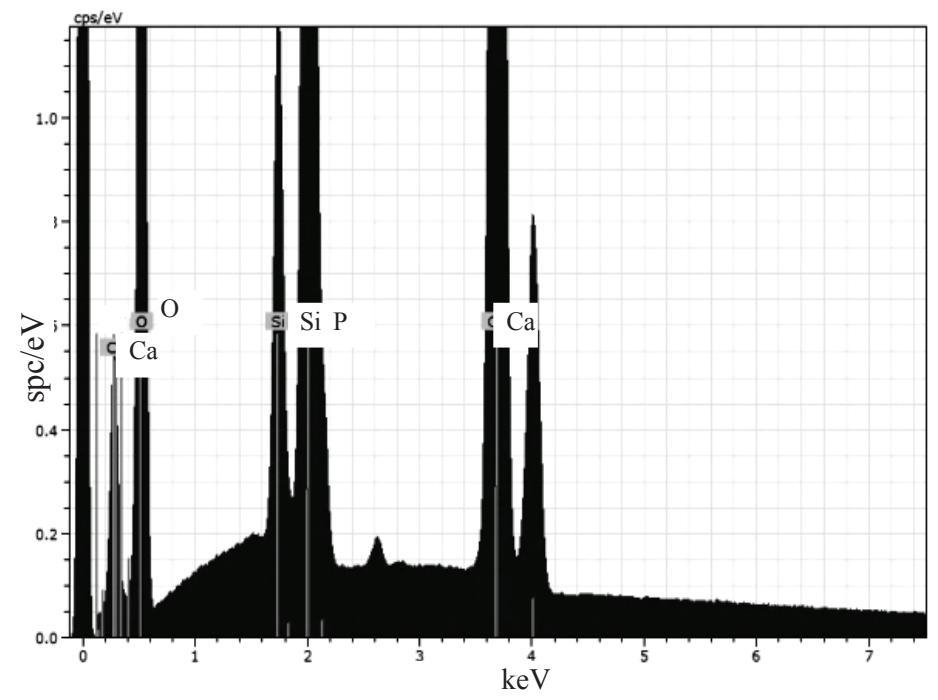

FIGURE 2. Spectrum of $\alpha$ and $\beta$ element lines in the precipitate filtered from FSS.

From atomic correlation at different points of the sample it implies that 1 molecule $\mathrm{SiO}_{2}$ corresponds to $4 \mathrm{CaHPO}_{4}$ molecule. Mixture of calcium hydrophosphate and silicon dioxide is a spherically shaped agglomerates composed of particle size of 9-12 um (Fig.3).

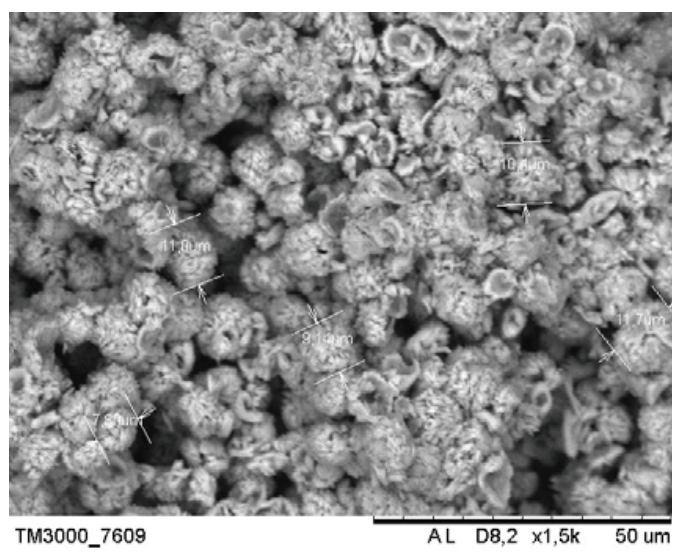

FIGURE 3. Photomicrograph of the precipitate.

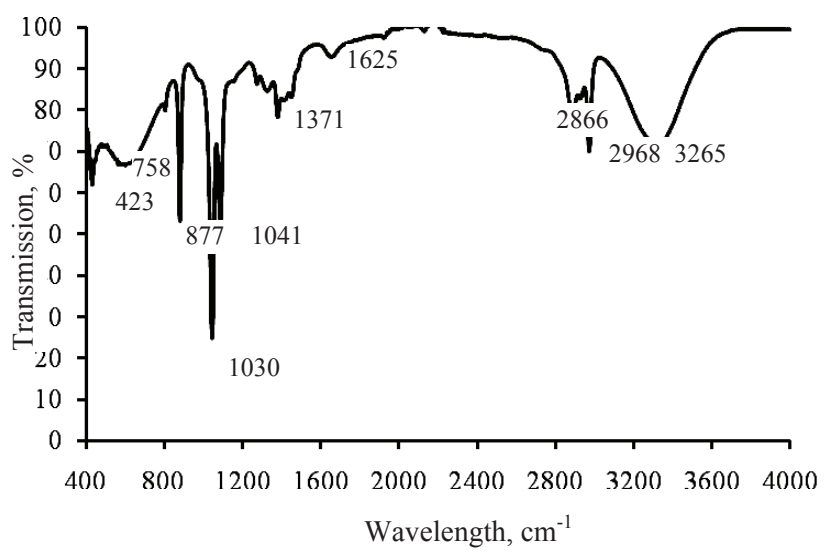

FIGURE 4. IR transmission spectrum of the FFS after removal of salt $\mathrm{CaHPO}_{4}$.

Phase of $\mathrm{SiO}_{2}$ in the sample which is a mixture $\mathrm{SiO}_{2}$ with $\mathrm{CaHPO}_{4}$ is not fixed due to the fact that its content is very small. According to IR spectroscopy (Fig. 4), in FFS after deposition of $\mathrm{CaHPO}_{4}$, in addition to tetraethoxysilane are calcium ions and phosphate ions.

In the IR spectra of this solution observed vibrations of phosphorus - oxygen bonds: $\mathrm{P}=\mathrm{O}(1371,1261$, $\left.1263 \mathrm{~cm}^{-1}\right), \mathrm{PO}_{4}\left(1030,1041 \mathrm{~cm}^{-1}\right), \mathrm{P}-\mathrm{O}-\mathrm{P}\left(877 \mathrm{~cm}^{-1}\right)$; and the vibrations of Ca-O $\left(423 \mathrm{~cm}^{-1}\right)$ signal, which is observed in the hydrogen phosphate of calcium. In addition, there are vibrations in the bonds of molecules of ethanol, water, and tetraethoxysilane $\left[\mathrm{H}-\mathrm{O}-\mathrm{H}\left(3265,1625 \mathrm{~cm}^{-1}\right), \mathrm{Si}-\mathrm{O}-\mathrm{H}\left(3265 \mathrm{~cm}^{-1}\right),-\mathrm{CH}_{2},-\mathrm{CH}_{3}(2866\right.$, $\left.2968 \mathrm{~cm}^{-1}\right)$, and $\left.\mathrm{Si}-\mathrm{O}-\mathrm{Si}\left(758 \mathrm{~cm}^{-1}\right)\right]$. Consequently, complete precipitation of salt from FFS not occurs. Solubility of salt in $96 \%$ ethanol at room temperature is $0.009 \mathrm{~mol} / 1(\operatorname{lgSP}=4.1)$. Thus, calcium hydroxyapatite precipitates after exposure of FFS during one day, and solution was after filtration contains, in addition to TEOS, alcohol, and water, calcium salt and orthophosphorous acid which interacts each with other. In the solution exist colloidal particles. It is defined with electrophoretic method that the colloidal particles of solution have positive charge. Assumed composition of the colloidal particle present a nucleus consisting of poor soluble calcium hydrophosphate and calcium ions adsorbed on its surface. Counter-ions in adsorption layer can be presented by $\mathrm{Si}\left(\mathrm{OC}_{2} \mathrm{H}_{5}\right)_{3} \mathrm{OH}_{2}^{+}$cations and in diffuse layer - with chlorine ions:

$$
\left\{\left[\mathrm{mCaHPO}_{4}\right] \mathrm{nCa}^{2+} \mathrm{xSi}\left(\mathrm{OC}_{2} \mathrm{H}_{5}\right)_{3} \mathrm{OH}_{2}^{+}\right\}^{(2 \mathrm{n}-\mathrm{x}) 2+}(\mathrm{n}-\mathrm{x}) \mathrm{Cl}^{-} \text {. }
$$


The formation of the particles $\mathrm{Si}\left(\mathrm{OC}_{2} \mathrm{H}_{5}\right)_{3} \mathrm{OH}_{2}{ }^{+}$occurs by the hydrolysis of $\mathrm{Si}\left(\mathrm{OC}_{2} \mathrm{H}_{5}\right)_{4}$ in $96 \%$ ethanol and protonation $\mathrm{HCl}$ :

$$
\begin{gathered}
\mathrm{Si}\left(\mathrm{OC}_{2} \mathrm{H}_{5}\right)_{4}+\mathrm{H}_{2} \mathrm{O}=\mathrm{Si}\left(\mathrm{OC}_{2} \mathrm{H}_{5}\right)_{3} \mathrm{OH}+\mathrm{C}_{2} \mathrm{H}_{5} \mathrm{OH} ; \\
\mathrm{Si}\left(\mathrm{OC}_{2} \mathrm{H}_{5}\right)_{3} \mathrm{OH}+\mathrm{HCl}=\mathrm{Si}\left(\mathrm{OC}_{2} \mathrm{H}_{5}\right)_{3} \mathrm{OH}_{2}^{+}+\mathrm{Cl}^{-} .
\end{gathered}
$$

As can we see from the Table 3, solution, which has been exposed for 4 days after separation of solid phase $\left(\mathrm{CaHPO}_{4}\right)$ with filtration, contain the colloidal particles with size in the range of 298 up to $334 \mathrm{~nm}$. Size of these particles decreases with time an on 9th day after FFS exposure their radius is 198-250 nm, and on 18th day $162-183 \mathrm{~nm}$ (Table 3).

TABLE 3. Data of PCS method for FFS after separation of solid phase $\mathrm{CaHPO}_{4}$.

\begin{tabular}{ccc}
\hline Maturing time of "mother liquor", days & $\boldsymbol{\tau}_{\mathbf{a}}$, cs & Radius of the particles, $\mathbf{n m}$ \\
\hline 4 & 67 & 325 \\
4 & 103 & 334 \\
4 & 181 & 298 \\
4 & 214 & 321 \\
4 & 145 & 198 \\
9 & 186 & 208 \\
9 & 265 & 245 \\
9 & 300 & 250 \\
18 & 362 & 162 \\
18 & 416 & 178 \\
18 & 447 & 183 \\
18 & 480 & 179 \\
\hline
\end{tabular}

TABLE 4. Results of quantitative X-ray spectral analysis of dried mother liquor.

\begin{tabular}{ccccc}
\hline \multicolumn{5}{c}{ Chemical content, at. \% } \\
\hline $\mathbf{C a}$ & $\mathbf{P}$ & $\mathbf{C l}$ & $\mathbf{S i}$ & $\mathbf{O}$ \\
\hline $6.24 \pm 0.02$ & $2.09 \pm 0.01$ & $5.97 \pm 0.02$ & $15.94 \pm 0.03$ & $69.82 \pm 0.09$ \\
\hline
\end{tabular}

According to X-ray data, dried solution at temperature $60{ }^{\circ} \mathrm{C}$, which was obtained after precipitation $\mathrm{CaHPO}_{4}$, represents mixture of two crystalline substances: $\mathrm{CaClH}_{2} \mathrm{PO}_{4}-\mathrm{H}_{2} \mathrm{O}$ and $\mathrm{SiO}_{2}$ (Fig. 5).

Calcium dihydrophosphate chloride is crystallized in monocline structure with lattice parameters: $a=5.76$ $\AA, b=17.13 \AA, c=6.41 \AA$. Silica is crystallized in structure of cubic with lattice parameters: $a=b=c=12,17$ $\AA$. Appearance of diffractogram does not exclude presence of other calcium salts in X-ray amorphous phase. Presence of $\mathrm{CaClH}_{2} \mathrm{PO}_{4}$ in dried FFS is explained by the processes proceeding in FFS. As it is shown above, the precipitate $\mathrm{CaHPO}_{4}$, which is formed according to the reaction equation:

$$
\mathrm{CaCl}_{2}+\mathrm{H}_{3} \mathrm{PO}_{4}=\mathrm{CaHPO}_{4}+2 \mathrm{HCl}
$$

drops out from FFS after its exposure within one day. At that acidity of mother liquor increases and equilibrium of dissociation of dihydrophosphate ion:

$$
\mathrm{H}_{2} \mathrm{PO}_{4}^{-}=\mathrm{H}^{+}+\mathrm{HPO}_{4}{ }^{2-}
$$

shifts in the side of formation of $\mathrm{H}_{2} \mathrm{PO}_{4}{ }^{-}$which forms $\mathrm{CaClH}_{2} \mathrm{PO}_{4}$ salt with calcium chloride.

Results of quantitative (Table 4) and qualitative (Fig. 6) micro X-ray spectral analysis indicate presence of $\mathrm{Ca}, \mathrm{Cl}, \mathrm{P}, \mathrm{O}$ and $\mathrm{Si}$ elements in each point of the sample. 


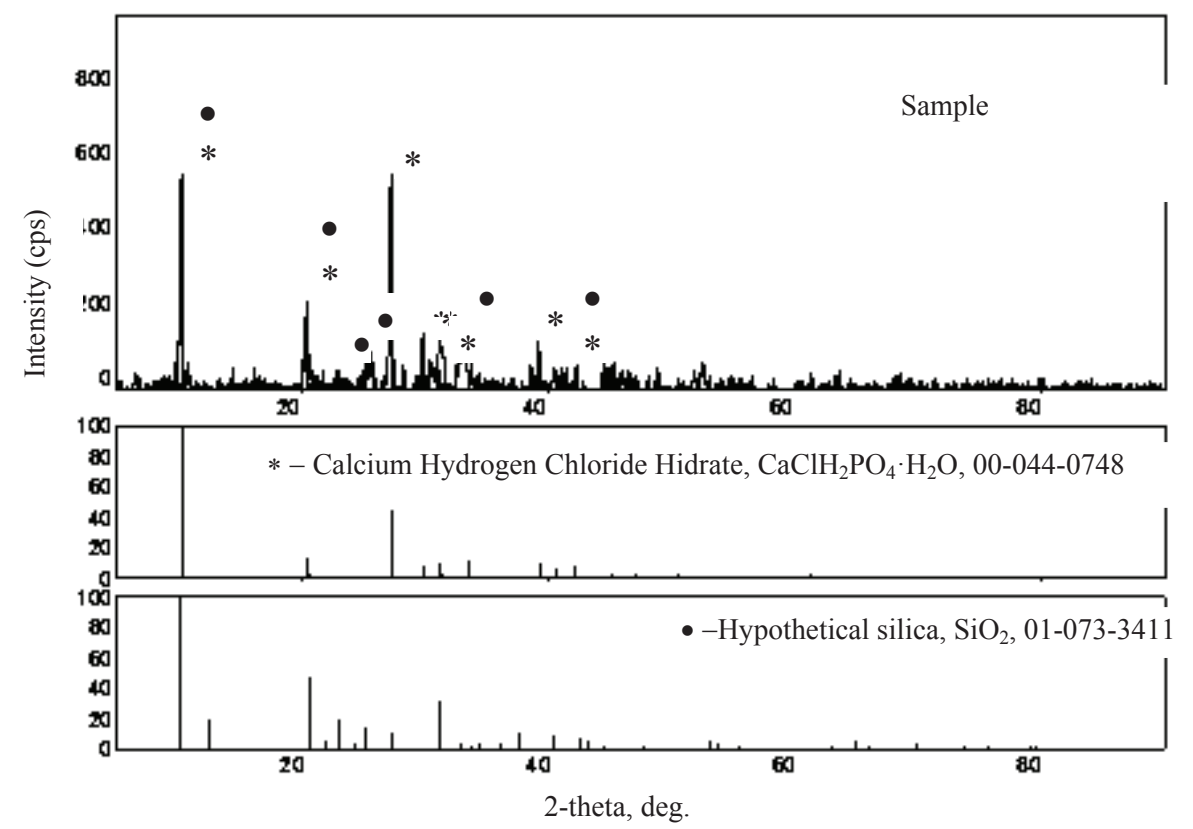

FIGURE 5. X-ray photograph of dried FFS after separation of solid phase $\left(\mathrm{CaHPO}_{4}\right)$.

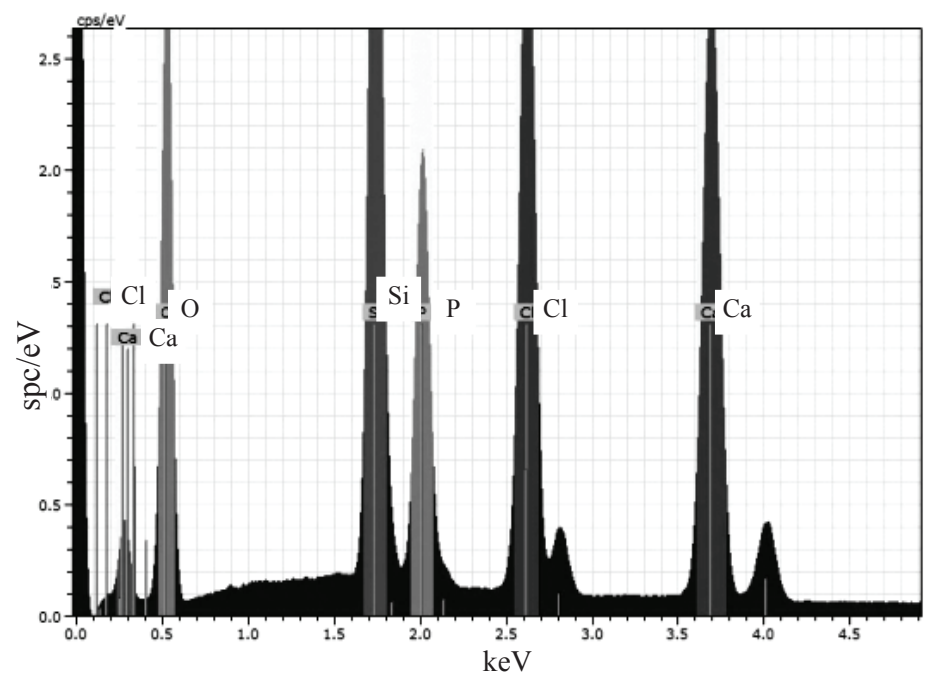

FIGURE 6. Spectrum of $\alpha$ and $\beta$ element lines in dried FFS after separation of solid phase $\left(\mathrm{CaHPO}_{4}\right)$

Quantitative ratio of their atoms $\mathrm{Ca}: \mathrm{Cl}: \mathrm{P}: \mathrm{O}: \mathrm{Si}=3: 3: 1: 8: 31$ also proves that dried mother solution contains besides compounds of $\mathrm{SiO}_{2}$ and $\mathrm{CaClH}_{2} \mathrm{PO}_{4} \cdot \mathrm{H}_{2} \mathrm{O}$ other substances. As we can see from Fig. 7, dried FFS after deposition of $\mathrm{CaHPO}_{4}$ represents porous structure with pore diameter of $0.67-1.51 \mu \mathrm{m}$. 


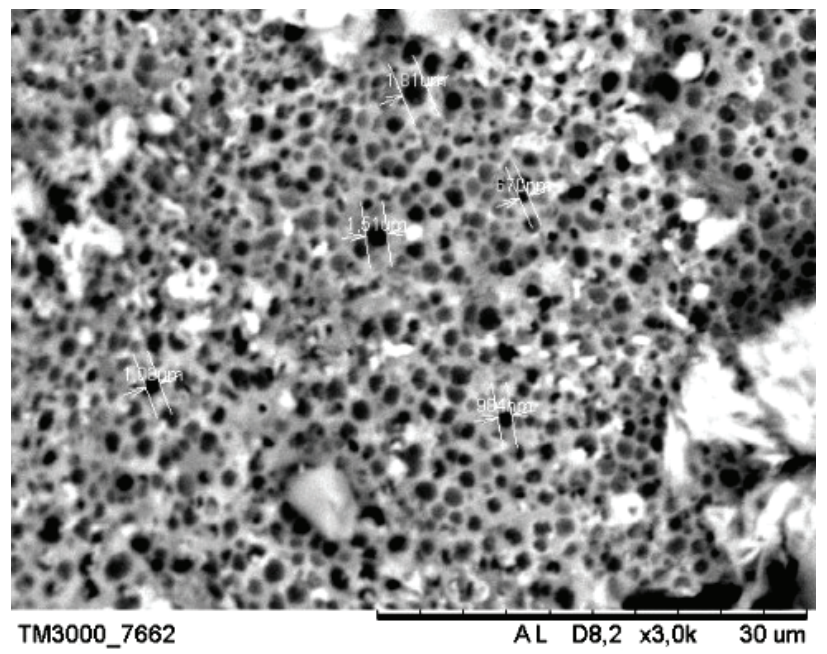

FIGURE 7. Photomicrograph of dried mother solution.

This solution maintains film forming ability and allows to form films with thickness of $62-83 \mathrm{~nm}$ and refractive index of 1.39-1.38.

\section{CONCLUSION}

Formation of solution based on the ethanol, TEOS, calcium chloride and orthophosphoric acid includes chemical processes as 1) interaction of calcium chloride with orthophosphoric acid with formation of poor soluble calcium hydrophosphate which drops out in the precipitate after exposure of FFS more than one day; 2) formation of positively charged micelle of presumable composition $\left\{\left[\mathrm{mCaHPO}_{4}\right] \mathrm{nCa}^{2+}\right.$ $\left.\mathrm{xSi}\left(\mathrm{OC}_{2} \mathrm{H}_{5}\right)_{3} \mathrm{OH}^{2+}\right\}^{(2 \mathrm{n}-\mathrm{x})}+2(\mathrm{n}-\mathrm{x}) \mathrm{Cl}^{-}$which is destructed in the process of drying at $60{ }^{\circ} \mathrm{C}$ with formation of solid phase which contains crystalline compounds with composition $\mathrm{CaClH}_{2} \mathrm{PO}_{4} \cdot \mathrm{H}_{2} \mathrm{O}$ and $\mathrm{SiO}_{2}$ and substances in amorphous state with elemental composition: $\mathrm{Ca}, \mathrm{Cl}, \mathrm{P}, \mathrm{O}$, and $\mathrm{Si}$ which form pores with diameter of $0.67-1.51$ $\mu \mathrm{m}$. To obtain calcium phosphate films with thickness less than $100 \mathrm{~nm}$ it is necessary to use FFS after its 9 day exposure, where the sizes of colloidal particles do not exceed $300 \mathrm{~nm}$.

\section{REFERENCES}

1. J. W. Park, K. B. Park and J. Y. Suh, Biomaterials. 28, 3306-3313 (2007).

2. S. Rammelt, T. Illert, S. Bierbaum, D. Scharnweber, H. Zwipp and W. Schneiders, Biomater. 27, 55615571 (2006).

3. Z. Schwartz, C. H. Lohmann, J. Oefinger, L. F. Bonewald, D. D. Dean and B. D. Boyan, Adv. Dent. Res. 13, 38-48 (1999).

4. J. Lincks, B. D. Boyan, C. R. Blanchard, C. H. Lohmann, Y. Liu, D. L. Cochran, D .D. Dean and Z. Schwartz, Biomater. 19, 2219-2232 (1998).

5. S. Lossdorfer, Z. Schwartz, L. Wang, C. H. Lohmann, J. D. Turner, M. Wieland, D. L. Cochran and B. D. Boyan, J. Biomed. Mater. Res. A. 70, 361-369 (2004).

6. R. Olivares-Navarrete, S. L. Hyzy, D. L. Hutton, C. P. Erdman, M. Wieland and B. D. Boyan, Biomater. 31, 2728-2735 (2010).

7. L. P. Borilo, T. S. Petrovskaya and E. S. Lyutova, Inorg. Mater. 50, 8, 810-816 (2014).

8. M. Jokinen, H. Rahial and J. B. Rosenholm, J. Sol-Gel Sci. Technol. 12, 3, 159-167 (1998).

9. M. Elisa, I. C. Vasiliu, B. A. Sava, F. Nastase, C. Nastase, A. Volceanov, V. Dima, S. Stoleriu and M. Eftimie, Phys. Chem. Glasses: Eur. J. Glass. Sci. Technol. B. 51, 6, 309-317 (2010.)

10. W. Liu and H. Zhan, Mater. Sci. Eng. 32, 4, 707-711 (2012). 